\title{
Progesterone inhibition of the development of the luteolytic signal in cows
}

\author{
G. E. Mann and G. E. Lamming \\ Department of Physiology and Environmental Science, University of Nottingham, Sutton Bonington, \\ Loughborough, Leics. LE12 5RD, UK
}

\begin{abstract}
Mated cows that subsequently undergo luteolysis have significantly lower plasma concentrations of progesterone than do cows in which pregnancy is maintained. Two groups of ovariectomized cows were treated with progesterone and oestradiol to recreate luteal phases exhibiting the extremes of plasma concentrations of progesterone $(6.0 \pm 0.4$ and $12.4 \pm 0.8 \mathrm{ng} \mathrm{ml}^{-1}$ ) normally seen in intact cows. The effect of this difference in progesterone on the development of the luteolytic signal was determined by monitoring the basal and oxytocin-stimulated plasma concentrations of the principal metabolite of prostaglandin $\mathrm{F}_{2 \alpha^{\prime}}$ PGFM on days $12-16$ of the simulated luteal phases. Basal PGFM concentrations were similar in the low and high progesterone groups on all days. The mean plasma concentration of PGFM showed a larger increase following oxytocin in the low progesterone group on days 13 and $14(P<0.05)$ and on days 15 and $16(P<0.1)$. These results demonstrate that a low plasma concentration of progesterone results in the development of a stronger luteolytic signal, and provide an explanation for the fact that cows with lower plasma concentrations of progesterone are more prone to embryo loss.
\end{abstract}

\section{Introduction}

In cattle, the successful establishment of pregnancy depends upon a fine balance between the timing of development of the luteolytic mechanism in the mother and the production of antiluteolytic trophoblastic interferon by the conceptus. Failure of this balance results in embryo loss, which continues to represent a major cause of reproductive loss, with $28 \%$ of dairy cows losing their embryos by day 25 after mating (Lamming et al., 1989).

During the early stages of pregnancy, progesterone stimulates the production of the endometrial secretions necessary for embryo development (Geisert et al., 1992), and controls the development of the luteolytic mechanism (for review see Silvia et al., 1991). In mated animals that subsequently undergo luteolysis, progesterone concentrations in both plasma and milk are lower during the second half of the luteal phase than in those cows that become pregnant (Lukesewska and Hansel, 1980; Lamming et al., 1989; Mann et al., 1995). This finding suggests that the concentration of progesterone may be a vital factor in determining the success or failure of pregnancy. However, it remains to be determined whether this difference in progesterone concentration is a result of factors leading to the failure of pregnancy or is an actual cause of early embryo loss.

Treatment of ovariectomized cows with progesterone and oestradiol results in the development of an active population of endometrial oxytocin receptors and $\mathrm{PGF}_{2 \alpha}$ release to exogenous oxytocin challenge, analogous to the luteolytic signal in intact animals (Lamming and Mann, 1995). In this study, the

Revised manuscript received 1 February 1995. low and high extremes of plasma progesterone normally seen during the luteal phase of intact cows were recreated in ovariectomized cows to investigate whether this difference affects the development of the luteolytic signal.

\section{Materials and Methods}

\section{Experimental animals}

The experiment was undertaken in mature Blue-Grey cows, ovariectomized several months previously, that had received a steroid hormone pretreatment regimen comprising 14 days of 'luteal phase' progesterone followed by 2 days of 'follicular phase' oestradiol. The progesterone pretreatment was given via an intravaginal progesterone releasing device (CIDR-B: SmithKline Beecham Animal Health, Tadworth). The oestradiol treatment was initiated on the morning of CIDR withdrawal and consisted of $6 \mathrm{i} . \mathrm{m}$. injections of a solution of oestradiol (Sigma Chemical Co., Poole) in corn oil $(25,50,75,100,100$ and $100 \mu \mathrm{g}$ oestradiol, respectively) at intervals of $8 \mathrm{~h}$ over $40 \mathrm{~h}$. This treatment regimen has been shown to produce a situation equivalent to a normal early luteal phase in intact cyclic animals, with low endometrial oxytocin receptor concentrations and no $\mathrm{PGF}_{2 \alpha}$ response to an oxytocin challenge (Lamming and Mann, 1995). The timing of subsequent treatments was defined relative to the second day of oestradiol pretreatment (defined as day 0) on which all cows demonstrated behavioural oestrus. Animals were then treated with progesterone and oestradiol for 16 days in a pattern designed to mimic the luteal phase up to the time of luteal regression. 
Table 1. Daily doses of progesterone administered to ovariectomized cows during a simulated luteal phase in low and high progesterone groups

\begin{tabular}{lcc}
\hline $\begin{array}{l}\text { Day of } \\
\text { simulated } \\
\text { cycle }\end{array}$ & \multicolumn{2}{c}{ Daily progesterone (mg) } \\
& Low group & High group \\
\hline $1-2$ & 0 & 0 \\
3 & 40 & 40 \\
4 & 80 & 80 \\
5 & 160 & 160 \\
6 & 160 & 240 \\
7 & 160 & 320 \\
$8-16$ & 160 & 400 \\
\hline
\end{tabular}

\section{Experimental design}

The experiment was carried out in two groups of four cows given either high $(n=4)$ or low $(n=4)$ concentrations of progesterone via i.m. injections twice a day in corn oil according to the protocol shown in Table 1 . In addition, all cows received oestradiol via a single s.c. implant (Lamming and Mann, 1995) inserted on the day of induced oestrus. The effects of hormone treatments on basal $\mathrm{PGF}_{2 u}$ production were monitored by measurement of the concentration of PGFM, the principal metabolite of $\mathrm{PGF}_{2 \mathrm{a}^{\prime}}$ in plasma samples collected at intervals of $30 \mathrm{~min}$ for $6 \mathrm{~h}$ on days $12-16$ of treatment. The development of endometrial responsiveness to oxytocin was monitored daily from day 12 to day 16 by measurement of PGFM concentrations in plasma samples collected before and after administration of exogenous oxytocin challenges.

\section{Blood sampling and oxytocin challenges}

Before the insertion of jugular cannulae for the oxytocin challenges, blood samples were collected by jugular venepuncture for steroid determination. On day 11 , the jugular vein of each animal was cannulated under local anaesthesia $(2 \mathrm{ml}$ lignocaine s.c., Lignovet $2 \%$; C-Vet, Bury St Edmunds, UK) with a $30 \mathrm{~cm}$ indwelling jugular catheter (i.d. $1.2 \mathrm{~mm}$, o.d. $1.8 \mathrm{~mm}$; Secalon universal tubing, BOC Health Care, Swindon), using a 12 gauge needle and $80 \mathrm{~cm}$ guide wire. Cannulae were then maintained for the duration of the experiment and used for the collection of all blood samples. On days 12-16, blood samples $(10 \mathrm{ml})$ were collected at intervals of $30 \mathrm{~min}$ for $6 \mathrm{~h}$ to monitor basal PGFM concentrations. Endometrial responsiveness to oxytocin was monitored by injecting cows i.v. with a single bolus of $50 \mathrm{iu}$ oxytocin (Hoechst UK Ltd, Milton Keynes) in $5 \mathrm{ml}$ saline, flushed in with a further $5 \mathrm{ml}$ saline. Plasma concentrations of PGFM were measured in blood samples collected at intervals of $20 \mathrm{~min}$ for $\mathrm{Ih}$ before the injection of oxytocin, and then at intervals of $10 \mathrm{~min}$ for the first $1 \mathrm{~h}$ after the challenge and at intervals of $20 \mathrm{~min}$ for a further $3 \mathrm{~h}$. Samples were collected into heparinized tubes, centrifuged at $1500 \mathrm{~g}$ for $10 \mathrm{~min}$ and the plasma was stored at $-20^{\circ} \mathrm{C}$.

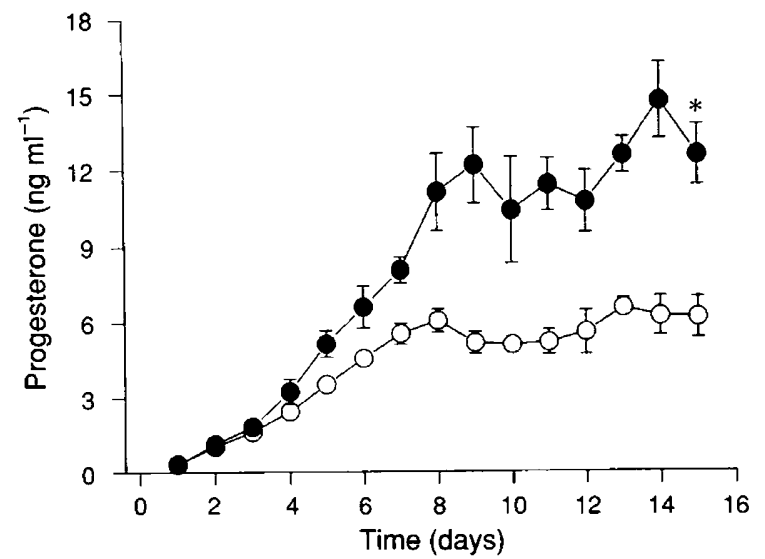

Fig. 1. Mean ( \pm SEM) plasma concentration of progesterone in ovariectomized cows treated with low $(0 ; n=4)$ or high $(0 ; n=4)$ doses of progesterone $\left({ }^{*} P<0.01\right.$ compared with low progesterone group; analysis of variance).

\section{Assays}

Plasma samples were assayed for PGFM after extraction with acidified diethyl ether by radioimmunoassay (Kaker et al., 1984). Intra- and interassay coefficients of variation were $<15 \%$ and $12.6 \%$, respectively. Progesterone was measured in plasma samples after extraction with petroleum ether by radioimmunoassay (Haresign et al., 1975). Intra- and interassay coefficients of variation were $<10 \%$ and $9.7 \%$, respectively. Oestradiol was measured in plasma using a modified radioimmunoassay kit (Serono Diagnostics Ltd, Woking; Mann et al., 1995). The sensitivity of the assay was $0.5 \mathrm{pg} \mathrm{ml}^{-1}$ and the intra- and interassay coefficients of variation were $<10 \%$ and $6.4 \%$, respectively.

\section{Statistical analyses}

Plasma concentrations of progesterone and changes in plasma concentration of PGFM following oxytocin challenge were analysed by repeated sample analysis of variance. Significant responses to oxytocin were defined as having occurred when the concentration of PGFM at three consecutive time points following the bolus challenge was greater than the pretreatment mean $+2 \mathrm{SD}$, and were defined as having ended when the concentration in a single sample fell below this concentration. The individual characteristics of the oxytocin challenge responses (mean concentration and duration) were then analysed using Student's $t$ tests on data that had been log transformed to reduce heterogeneity of variance.

\section{Results}

Plasma concentrations of progesterone were similar in the low and high progesterone groups up to day 5 (Fig. 1). However, from day 6 the plasma concentration of progesterone was significantly $(P<0.01)$ higher in the high progesterone group, reaching a mean concentration between day 9 and day 16 of $12.4 \pm 0.8 \mathrm{ng} \mathrm{ml}^{-1}$ compared with $6.0 \pm 0.4 \mathrm{ng} \mathrm{ml}^{-1}$ in the low group. The mean ( \pm SEM) plasma concentration of oestradiol maintained over this period was $1.9 \pm 0.3 \mathrm{pg} \mathrm{ml}^{-1}$. 


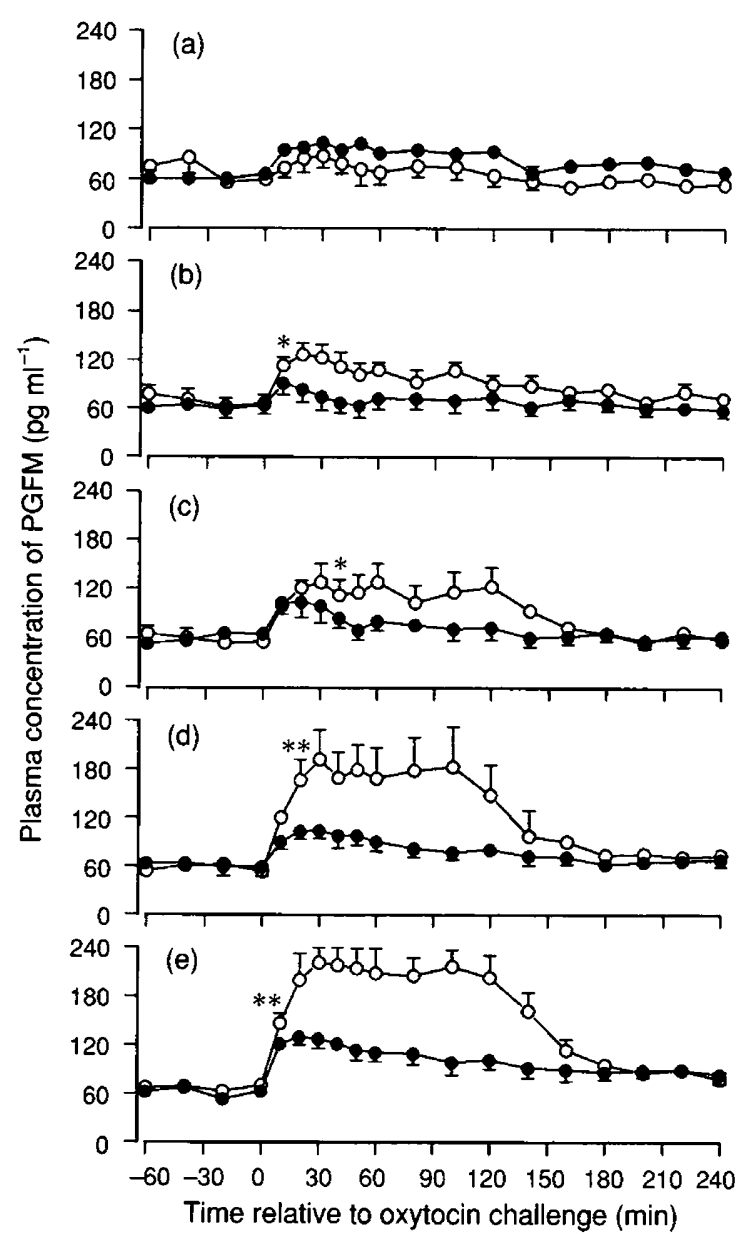

Fig. 2. Mean ( \pm SEM) plasma concentrations of PGFM, the principal metabolite of prostaglandin $F_{2 \alpha}$, before and after injection of 50 iu oxytocin in ovariectomized cows treated with low (o; $n=4)$ or high $(\bullet ; n=4$ ) doses of progesterone on (a) day 12, (b) day 13 , (c) day 14 , (d) day 15 and (e) day 16 of a simulated luteal phase $\left({ }^{*} P<0.05\right.$, $* * P<0.01$ compared with high group; analysis of variance).

On day 12, plasma concentrations of PGFM showed no significant changes following oxytocin challenge in either group (Fig. 2). In the high progesterone group, significant rises in the plasma concentration of PGFM were seen on days 14,15 and $16(P<0.05)$, while in the low progesterone group significant rises were seen on day $13(P<0.05)$ as well as on days $14 \quad(P<0.05), 15$ and $16 \quad(P<0.01)$. These increases in PGFM were consistently higher in the low progesterone group (days 13 and $14, P<0.05$; days 15 and 16, $P<0.01$ ).

Basal PGFM concentration was similar in both groups at all time points (low progesterone group $74.5 \pm 1.6 \mathrm{pg} \mathrm{ml}^{-1}$; high progesterone group $77.0 \pm 2.1 \mathrm{pg} \mathrm{ml}^{-1}$ ). Consistent responses to oxytocin were not seen in all the cows in a particular group until day 14 in the low progesterone group and day 15 in the high progesterone group. The individual characteristics of these responses are shown in Table 2. The duration of the response to oxytocin was longer $(P<0.05)$ in the low progesterone group on day 15 but not on day 16. However, the magnitude of response was greater in the low progesterone group on day 15 and 16.
Table 2. Mean ( \pm SEM) characteristics of the responses to oxytocin challenge seen on days 14-16 of a simulated luteal phase in ovariectomized cows treated with either low $(n=4)$ or high $(n=4)$ doses of progesterone

\begin{tabular}{lccrcc}
\hline & \multicolumn{2}{c}{ Mean response $(\%$ basal) } & & \multicolumn{2}{c}{ Response duration (min) } \\
\cline { 2 - 3 } \cline { 5 - 6 } Day & \multicolumn{1}{c}{ Low } & High & & Low & High \\
\hline 14 & $59.5 \pm 28.1$ & - & & $95 \pm 38$ & - \\
15 & $126.0 \pm 39.9$ & $33.0 \pm 13.4^{*}$ & & $140 \pm 30$ & $58 \pm 31^{*}$ \\
16 & $135.5 \pm 42.3$ & $42.3 \pm 6.5^{*}$ & & $185 \pm 22$ & $195 \pm 29$ \\
\hline
\end{tabular}

${ }^{*} P<0.05$ compared with low group (Student's $t$ test on log-transformed data).

\section{Discussion}

The ability of progesterone to influence both embryo development and luteolysis is well documented (for reviews see Silvia et al., 1991; Geisert et al, 1992), as is the fact that in mated cows that subsequently undergo luteolysis, progesterone concentrations are lower than in those cows that remain pregnant (Lukesewska and Hansel, 1980; Lamming et al., 1989; Mann et al., 1995). While it has been postulated that during early pregnancy either the embryo or some other factor associated with pregnancy may have a luteotrophic action on the corpus luteum, the main difference in progesterone concentration between pregnant and inseminated nonpregnant cows is an inherent one, as the mean concentration in cyclic cows lies midway between the mean for the two mated groups (Lamming et al., 1989).

While it has been established that cows with an inherently lower plasma concentration of progesterone are more likely to lose their pregnancy, it remains to be determined whether this low concentration of progesterone is the cause of pregnancy failure or is merely a manifestation of other factors leading to increased embryo loss. Furthermore, if the low concentration of progesterone is causally related to embryo loss, it can only be hypothesized as to whether the effect of this difference in progesterone acts on the development of the embryo or on the development of the luteolytic mechanism in the mother. The results of this study, in which the effects of progesterone on the development of the luteolytic mechanism have been investigated in isolation from other confounding factors, provide direct evidence that in cows with a lower concentration of progesterone, the development of the luteolytic signal occurs more strongly than in cows with a higher progesterone concentration. In inseminated cows that fail to become pregnant, luteolysis does not occur early, as the fall in progesterone in these cows occurs at the same time as in cyclic cows (Lamming et al., 1989). The effect of the lower concentration of progesterone must be on the strength rather than the timing of luteolysis. While it has also been demonstrated that progesterone can affect embryo development (Geisert et al., 1992), it has yet to be shown conclusively whether the lower luteal phase progesterone concentrations observed in mated cows that fail to become pregnant is sufficient to impair embryonic production of the antiluteolytic signal, trophoblast interferon, thus rendering the pregnancy even less likely to succeed. 
While a low concentration of progesterone results in a stronger luteolytic signal, this does not mean that in all cases of low progesterone, embryo loss will occur or that in all cases of high progesterone, pregnancy will succeed. In the study of Mann et al. (1995), which demonstrated a significant difference in mean plasma progesterone concentration during early pregnancy between mated cows in which pregnancy was successful $\left(8.2 \pm 0.2 \mathrm{ng} \mathrm{ml}^{-1}\right)$ and those in which pregnancy failed $\left(6.6 \pm 0.2 \mathrm{ng} \mathrm{ml}^{-1}\right)$, the actual ranges of progesterone concentrations between day 12 and day 16 in the individual cows were $5.7-12.3 \mathrm{ng} \mathrm{ml}^{-1}$ in the pregnant group and 4.8 $10.5 \mathrm{ng} \mathrm{ml}^{-1}$ in the group in which pregnancy failed. Thus, maternal progesterone concentration should not be regarded as an absolute determinant of early pregnancy, but rather as a factor that influences the probability of success or failure.

Progesterone is responsible for the stimulation of a number of factors associated with the production of $\mathrm{PGF}_{2 \alpha^{\prime}}$ such as prostaglandin synthase activity (Salamonsen $e^{t}$ al., 1990), and in cows with a lower plasma concentration of progesterone, a reduction in $\mathrm{PGF}_{2 \alpha}$ release might therefore be expected. However, the important aspect of $\mathrm{PGF}_{2 \alpha}$ release for luteolysis is the generation of luteolytic spikes of release, a process requiring the presence of oxytocin receptors within the endometrium. One of the main actions of progesterone within the uterus is to inhibit the development of oxytocin receptors (Vallet and Lamming, 1991; Lau et al., 1992; Lamming and Mann, 1995) and so the lower concentration of progesterone in inseminated nonpregnant cows may permit earlier oxytocin receptor development and thus earlier production of luteolytic spikes of $\mathrm{PGF}_{2 a}$. Furthermore, in this study, basal PGFM concentrations were not affected by the level of progesterone replacement, suggesting that, provided sufficient progesterone is present, normal $\mathrm{PGF}_{2 \alpha}$ production can occur.

In intact cows, a lower concentration of progesterone results in a higher level of LH release, which in turn stimulates a greater production of oestradiol (Robertson et al., 1989). Oestradiol stimulates both the development of endometrial oxytocin receptors and the production of PGF PGeard and $_{2 \alpha}$ Lamming, 1994; Mann and Lamming, in press a). This suggests that, in intact cows, the adverse effects of lower progesterone concentration may be more severe than in the ovariectomized model, in which cows were administered a constant dose of oestradiol. However, careful monitoring of pregnant and inseminated nonpregnant cows failed to demonstrate any major difference in plasma oestradiol concentration (Lukesewska and Hansel, 1980; Mann et al., 1995).

Two hormonal treatment regimens have been used to improve the calving rate in cattle: progesterone supplementation at various times after mating; and administration of a bolus of the GnRH analogue, buserelin, 10-12 days after mating. Both strategies have yielded variable results. Treatment with buserelin, which causes a reduction in plasma oestradiol concentration (Mann and Lamming, in press b; Mann et al., 1995) and a reduction in $\mathrm{PGF}_{2 \alpha}$ production (G. E. Mann and G. E. Lamming, unpublished observations), can result in a significant improvement in calving rate (MacMillan et al., 1986; Peters et al., 1992), although in other triais this treatment has had no effect (Jubb et al., 1990; Ryan et al., 1994). It is possible that this variation may be related in part to endogenous progesterone patterns. However, in a study of plasma hormone concentrations in mated cows treated with buserelin 12 days after mating (Mann et al., 1995), a consistent fall in oestradiol was observed only in those cows that remained pregnant. In the group in which pregnancy failed, and plasma progesterone concentration was lower, no consistent fall in oestradiol was observed, suggesting that there is not an important interaction between the incidence of low plasma progesterone concentration and the success of buserelin treatment.

The second approach has been the use of progesterone supplementation, which, owing to the consistent observation of lower progesterone concentrations from day 10 to day 16 in mated cows in which pregnancy fails, and the demonstration of a direct effect of progesterone concentration on the strength of the luteolytic signal, should be expected to yield good results. However, the results of this approach to increasing pregnancy rate have also been highly variable. In many of these studies, progesterone administration has started early in the luteal phase, and has generally resulted in an improvement in conception rate, athough this has tended to be too small to achieve statistical significance (see Diskin and Sreenan, 1986 for review). However, the success of these studies is probably due to an improvement in maternal-embryo synchrony rather than the alleviation of luteal insufficiency later in the cycle. When progesterone was administered later in the cycle, usually from about day 10, despite a tendency to improve conception rate in certain studies, no consistent significant increases in conception rate have been achieved (Sreenan et al., 1979; Macmillan et al., 1991). An explanation of this lack of success may lie in the fact that in none of these studies has any attempt been made to produce a controlled increase in progesterone over the critical period from day 10 to day 17 , when the actual differences in progesterone become apparent between those cows in which pregnancy is successful and those in which pregnancy fails. Furthermore, if too much progesterone is administered, raising plasma concentrations too far, a reduction in the secretion of LH may occur, which reduces the luteotrophic support of the endogenous corpus luteum, and indeed a reduction in luteal mass has been reported (Diskin and Sreenan, 1986). In such circumstances, the withdrawal of the exogenous progesterone may then leave the corpus luteum unable to produce sufficient progesterone to support the continuation of pregnancy. However, with a more careful approach to defining the level and timing of progesterone supplementation required, a more consistent improvement in conception rate may be an achievable goal.

In conclusion, the results of this study provide direct evidence, that, in cows, a lower plasma concentration of progesterone leads to a stronger luteolytic signal. This stronger luteolytic drive provides a more difficult obstacle for a given embryo to overcome and thus predisposes certain cows to a higher incidence of embryo loss. This result suggests that the careful application of a suitable level of progesterone supplementation over an appropriate period should be a suitable technique by which to combat early embryo mortality in cows.

The authors thank S. Machin, C. Hinchcliffe, L. Hill and the staff of Nottingham University Joint Animal Breeding Unit for technical assistance. The work was supported by a grant from the Milk Marketing Board of England and Wales. The oxytocin was donated by Hoechst and the CIDR-B devices by SmithKline Beecham. 


\section{References}

Beard AP and Lamming GE (1994) Oestradiol concentration and the development of the oxytocin receptor and oxytocin-induced prostaglandin $F_{2 a}$ release in ewes Journal of Reproduction and Fertility 100 469-475

Diskin MG and Sreenan IM (1986) Progesterone and embryo survival in the cow. In Embryo Mortality in Farm Animals pp 142-158 Eds JM Sreenan and MG Diskin. Martinus Nijhoff, Dordrecht

Geisert RD, Morgan GL, Short EC and Zavy MT (1992) Endocrine events associated with endometrial function and conceptus development in cattle Reproduction Fertility and Development 4 301-305

Haresign W, Foster JP, Haynes NB, Crighton DB and Lamming GE (1975) Progesterone levels following treatment of seasonally anoestrous ewes with synthetic LH-releasing hormone Journal of Reproduction and Fertility 43 269-279

Jubb TF, Abhayaratne D, Malmo J and Anderson GA (1990) Failure of an intramuscular injection of an analogue of gonadotrophin releasing hormone (Buserelin) in 11-13 days post insemination to increase pregnancy rate in dairy cattle Australian Veterinary Journal 67 359-361

Kaker ML, Murray RD and Dobson H (1984) Plasma hormone changes in cows during induced or spontaneous calvings and the early post partum period Veferinary Record 115 378-382

Lamming GE and Mann GE (1995) Control of endometrial oxytocin receptors and prostaglandin $\mathrm{F}_{2 \mathrm{a}}$ production in the cow by progesterone and oestradiol Journal of Reproduction and Fertility 103 69-73

Lamming GE, Darwash AO and Back HL (1989) Corpus luteum function in dairy cows and embryo mortality Joumal of Reproduction and Fertility Supplement $37245-252$

Lau TM, Gow GB and Fairclough RJ (1992) Differential effects of progesterone treatment on the oxytocin-induced prostaglandin $\mathrm{F}_{2 \alpha}$ response and the levels of endometrial oxytocin receptors in ovariectomised ewes Biology of Reproduction 46 17-22

Lukesewska J and Hansel W (1980) Corpus luteum maintenance during early pregnancy in the cow Journal of Reproduction and Fertility 59 485-493

MacMillan KL, Taufa VK and Day AM (1986) Effects of an agonist of gonadotrophin releasing hormone (buserelin) in cattle. III. Pregnancy rates after a post-insemination injection during metoestrus or dioestrus Animal Reproduction Science 11 1-10
MacMillan KL, Taufa VK, Day AM and Peterson AJ (1991) Effects of supplementary progesterone on pregnancy rates in cattle. Journal of Reproduction and Fertility Supplement $\mathbf{4 3} 304$

Mann GE and Lamming GE Effect of the level of oestradiol on oxytocin-induced prostaglandin $F_{2 a}$ release in the cow Joumal of Endocrinology (in press a)

Mann GE and Lamming GE Effects of treatment with Buserelin on plasma concentrations of oestradiol and progesterone and cycle length in the cow British Veterinary Journal (in press b)

Mann GE, Lamming GE and Fray MD (1995) Plasma oestradiol during early pregnancy in the cow and the effects of treatment with buserelin Animal Reproduction Science 37 121-131

Peters AR, Drew SB, Mann GE, Lamming GE and Beck NFG (1992) Experimental and practical approaches to the establishment and maintenance of pregnancy Journal of Physiology and Pharmacology 43 (Supplement 1) 143-152

Robertson MS, Wolfe MW, Stumpf TT, Kittok RJ and Kinder JE (1989) Luteinizing hormone secretion and corpus luteum function in cows receiving two levels of progesterone Biology of Reproduction 41 997-1003

Ryan DP, Snijders S, Condon T, Grearly M, Sreenan J and O'Farrell KJ (1994) Endocrine and ovarian responses and pregnancy rates in dairy cows following administration of a gonadotrophin releasing hormone analog at the time of artificial insemination or at mid-cycle post insemination Animal Reproduction Science 34 179-191

Salamonsen LA, Hampton AL, Clements JA and Findlay JK (1990) Regulation of gene expression and cellular localization of prostaglandin synthase by oestrogen and progesterone in the ovine uterus Journal of Reproduction and Fertility 92 393-406

Silvia WJ, Lewis GS, McCracken JA, Thatcher WW and Wilson L (1991) Hormonal regulation of uterine secretion of prostaglandin $\mathrm{F}_{2 \alpha}$ during luteolysis in ruminants Biology of Reproduction 45 655-663

Sreenan JM, Diskin MG and Murphy M (1979) Fertilization and embryo survival rates in control and progesterone or hCG treated heifers Annales de Biologie Animale Biochemie Biophysique 19 1619-1623

Vallet JL and Lamming GE (1991) Ovine conceptus secretory protein and bovine recombinant interferon ${ }_{a 1}-1$ decrease endometrial oxytocin receptor concentrations in cyclic and progesterone-treated ovariectomised ewes Journal of Endocrinology $131475-482$ 